\title{
Knockdown of Bmi1 inhibits the stemness properties and tumorigenicity of human bladder cancer stem cell-like side population cells
}

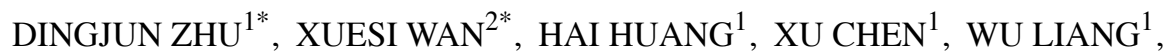 \\ FENGJIN ZHAO ${ }^{1}$, TIANXIN LIN ${ }^{1}$, JINLI HAN ${ }^{1}$ and WENLIAN XIE ${ }^{1}$ \\ ${ }^{1}$ Department of Urology, Sun Yat-Sen Memorial Hospital, Sun Yat-Sen University, Guangzhou 510120; \\ ${ }^{2}$ Department of Endocrinology, The First Affiliated Hospital of Sun Yat-sen University, Guangzhou 510080, P.R. China
}

Received September 22, 2013; Accepted November 11, 2013

DOI: $10.3892 /$ or.2013.2919

\begin{abstract}
B-cell-specific Moloney murine leukemia virus insertion site 1 (Bmi1) is directly involved in cell growth, proliferation and self-renewal of cancer stem cells (CSCs). The aim of the present study was to assess the role of Bmil in the maintenance of stemness properties and tumorigenicity of human bladder CSC-like side population (SP) cells. SP cells were sorted by flow cytometry using Hoechst 33342 staining. Bmil mRNA and protein expression in SP and non-SP (NSP) cells was analyzed by quantitative PCR, immunofluorescence and western blotting. The stemness properties of SP cells included cell proliferation, migration, self-renewal, chemotherapy resistance and cell cycle progression were assessed. Tumor formation was also assessed in human bladder cancer xenografts after Bmil silencing. The mRNA expression of Bmil was upregulated in SP cells when compared with that in the NSP cells. Knockdown of Bmil in SP cells resulted in inhibition of cell proliferation, migration and tumor sphere formation, enhanced sensitivity to cisplatin, and cell cycle arrest in the G0/G1 phase. Bmil knockdown inhibited cell cycle progression through derepression of the $\mathrm{p} 16^{\mathrm{INK} 4 \mathrm{a}} / \mathrm{p} 14^{\mathrm{ARF}}$ locus. Bmi1-siRNA SP cells failed to produce tumors in recipient mice, while typical urothelial carcinoma formed from subcutaneously injected scramble-siRNA SP cells. Bmi1 is crucial for the maintenance of stemness properties and tumorigenicity of human bladder CSC-like cells. Bmil may be a potential therapeutic target for the eradication of CSCs in bladder cancer.
\end{abstract}

Correspondence to: Dr Wenlian Xie, Department of Urology, Sun Yat-Sen Memorial Hospital, Sun Yat-Sen University, Guangzhou 510120, P.R. China

E-mail: xiewenlian2013@126.com

*Contributed equally

Key words: Bmi1, side population cells, cancer stem cells, bladder cancer, tumorigenicity

\section{Introduction}

Bladder cancer is the most common malignancy of the urinary system and the sixth most common cancer in China. The age-standardized incidence rate is 11.4 per 100,000 for men, and 3.51 per 100,000 for women (1). The incidence of bladder cancer is even higher in Western countries (2). Approximately $75 \%$ of bladder cancers are noninvasive cancers, which have a high rate of recurrence and progression. The remaining $25 \%$ of bladder cancers are muscle-invasive cancers and are associated with extremely poor prognosis despite systemic therapy (3). Although great advances have been achieved in the understanding of this disease, the molecular mechanisms involved in the development and progression of bladder cancer are still largely unknown.

Increasing evidence has demonstrated the existence of cancer stem cells (CSCs) in most cancers. The CSC hypothesis suggests that a minor population of tumor cells, termed cancer stem cells or tumor-initiating cells, share various properties with normal stem cells and possess tumorigenic potential, as well as self-renewal, differentiation, and proliferation capacities (4). CSCs seem to be chemoresistant and radioresistant, leading to local recurrence $(5,6)$.

Isolation of rare CSCs is an important step in CSC research. The most common method of CSC isolation is the use of specific surface markers, such as CD44, CD133, CD24, ESA and aldehyde dehydrogenase1 (ALDH1). Notably, the expression of CSC surface markers is specific to each tissue type, but some tumors do not have specific surface markers available for isolation. Side population (SP) cell analysis and sorting have been successfully used for the enrichment of stem cells in a variety of tissues $(5,7)$. SP cells isolated from diverse cancer cell lines harbor stem cell-like properties (7-9).

B-cell-specific Moloney murine leukemia virus insertion site 1 (Bmil) is a member of the Polycomb group (PcG) gene family, and was initially found to induce lymphoma upon cooperation with c-Myc by inhibiting c-Myc-induced apoptosis via $\mathrm{p} 16^{\mathrm{INK} 4 \mathrm{a}} / \mathrm{p} 14^{\mathrm{ARF}}(10,11)$. Bmil plays a critical role in the self-renewal and differentiation of a variety of normal stem cells and CSCs $(10,12)$. Recent studies suggest that Bmil is involved in cancer initiation, and targeting Bmil using gene 
therapy abolishes the chemoresistance of tumor cells $(10,13)$. However, we have limited understanding of the underlying mechanisms of Bmil function.

In the present study, we detected SP cells from the human bladder cancer cell line T24. These cells exhibited stem celllike properties, providing the foundation for further study on the molecular mechanism of bladder cancer. The objectives were then to examine the functional significance of Bmil in the maintenance of the stem cell-like properties of the SP subpopulation in T24 cells, and investigate whether Bmil is involved in the tumorigenicity of SP T24 cells in vivo. Results from our study may reveal the potential strategy for targeting Bmil for bladder cancer therapy.

\section{Materials and methods}

Cell culture. The human bladder cancer cell line T24 [American Type Culture Collection (ATCC), Manassas, VA, USA] was cultured in RMPI-1640 medium (Gibco, Invitrogen, Carlsbad, CA, USA), supplemented with $10 \%$ fetal bovine serum (FBS) (Gibco), $100 \mathrm{U} / \mathrm{ml}$ penicillin $\mathrm{G}$ and $100 \mu \mathrm{g} / \mathrm{ml}$ streptomycin. All cell lines were maintained in a humidified $5 \% \mathrm{CO}_{2}$ incubator at $37^{\circ} \mathrm{C}$.

Sorting of SP cells by flow cytometry using Hoechst 33342. T24 cells were resuspended in pre-warmed complete RPMI1640 medium at a concentration of $1 \times 10^{6}$ cells $/ \mathrm{ml}$. Cells were cultured either in the absence or in the presence of verapamil (50 $\mu \mathrm{mol} / 1$; Sigma, St. Louis, MO, USA) for $30 \mathrm{~min}$ at $37^{\circ} \mathrm{C}$, before adding the DNA-binding dye, Hoechst 33342 (Sigma), at a final concentration of $5 \mu \mathrm{g} / \mathrm{ml}$ and incubating for $90 \mathrm{~min}$ in the dark with gentle mixing. Cells were then washed twice with PBS and resuspended in ice-cold PBS/2\% FBS to a final concentration of $1 \times 10^{6}$ cells $/ \mathrm{ml}$. Propidium iodide (PI) ( $2 \mu \mathrm{g} / \mathrm{ml}$; Sigma) was added to gate viable cells, and the cells were maintained at $4^{\circ} \mathrm{C}$ in the dark before flow cytometry (Beckman Coulter, Brea, CA, USA) sorting. Hoechst 33342 was excited at $355 \mathrm{~nm}$ and a fluorescent profile was generated for dual-wavelength analysis (450/50 and 675/20 nm). We collected both SP and non-SP (NSP) cells to evaluate the sorting purity and to conduct further experiments.

Immunofluorescence analysis. Freshly isolated SP and NSP cells from the T24 cells were cultured on glass slides overnight. Cells were then fixed in $4 \%$ paraformaldehyde for $20 \mathrm{~min}$, incubated with $0.5 \%$ Triton-X in PBS for $5 \mathrm{~min}$, and blocked in $10 \%$ normal goat serum for $30 \mathrm{~min}$. After incubation, cells were stained with a primary antibody against Bmil (Santa Cruz Biotechnology, Santa Cruz, CA, USA), at a dilution of $1: 100$ for $12 \mathrm{~h}$ at $4^{\circ} \mathrm{C}$. Cells were then washed and incubated with FITC-conjugated goat anti-mouse IgG (Proteintech Group Inc., Chicago, IL, USA) at a dilution of 1:200 for $1 \mathrm{~h}$ at room temperature. After washing in PBS, cells were coverslipped with a mounting medium containing 4',6-diamidino-2-phenylindole (DAPI). Stained cells were examined under a BX51 laser scanning confocal microscope (Olympus, Tokyo, Japan).

Small-interfering RNA transfection. Specific siRNA targeting human Bmil cDNA (GenBank no. NM_005180.8) (5'-CCU
CCA CCU CUU CUU GUU UTT-3') named Bmil-siRNA and a scramble-siRNA (5'-UUC UCC GAA CGU GUC ACG UTT-3') were synthesized by GenePharma (Shanghai, China). siRNAs (100 nM) were transfected into T24 cells or SP cells sorted from T24 cells using Lipofectamine 2000 (Invitrogen), according to the manufacturer's instructions. Transfection efficiency was then assessed using quantitative real-time RT-PCR and western blotting for Bmil. Transfected cells were cultured for further experiments.

Real-time RT-PCR analysis. Total RNA was extracted from cells using TRIzol (Invitrogen). RNA purity was determined using absorbance at 260 and $280 \mathrm{~nm}$ (A260/280), and the integrity of the RNA was verified by electrophoresis on formaldehyde gels. Each sample $(1 \mu \mathrm{g})$ was reverse transcribed using a RT-PCR kit (Takara Bio, Otsu, Japan). Real-time PCR analysis was performed using a standard SYBR Green PCR kit (Roche Applied Science, Penzberg, Germany) on a LightCycler 480 real-time PCR system (Roche Diagnostics, Basel, Switzerland), according to the manufacturer's instructions. RNA levels of the GAPDH gene were monitored as an internal control. Primer sequences were: GAPDH, forward 5'-AAG GTG AAG GTC GGA GTC AAC-3' and reverse 5'-GGG GTC ATT GAT GGC AAC AAT A-3'; Bmil, forward 5'-CGT GTA TTG TTC GTT ACC TGG A-3' and reverse 5'-TTC AGT AGT GGT CTG GTC TTG T-3'; p14ARF, forward 5'-ATG GAG CCT TCG GCT GAC T-3' and reverse 5'-GTA ACT ATT CGG TGC GTT GGG-3'; p16INK4a, forward 5'-GGG TTT TCG TGG TTC ACA TCC-3' and reverse 5'-CTA GAC GCT GGC TCC TCA GTA-3'; Oct4, forward 5'-CTT GAA TCC CGA ATG GAA AGG G-3' and reverse 5'-GTG TAT ATC CCA GGG TGA TCC TC-3'; ABCG2, forward 5'-ACG AAC GGA TTA ACA GGG TCA-3' and reverse 5'-CTC CAG ACA CAC CAC GGA T-3'. The relative expression was calculated using the $2^{-\Delta \Delta C t}$ method.

Western blotting. Equal amounts of protein lysates $(20 \mu \mathrm{g})$ were subjected to SDS-PAGE and transferred to a PVDF membrane by electroblotting. Antibodies against Bmi1 (1:2,000 dilution; Santa Cruz Biotechnology), P14 ${ }^{\text {ARF }}$ (1:2,000 dilution; Abcam, USA) and P16 ${ }^{\text {INK4a }}$ (1:1,000 dilution, Abcam) were used as the primary antibodies. An anti- $\beta$-actin antibody at a $1: 10,000$ dilution was used as a loading control. The protein bands were visualized using an imaging system (Bio-Rad, Hercules, CA, USA).

Cell proliferation assays. Cells were plated at a density of $1 \times 10^{3}$ cells/well in complete RPMI-1640, in triplicate, in a 96-well plate $(100 \mu \mathrm{l} /$ well $)$ and incubated over 7 days. The cell titer 3-(4,5-dimethylthiazol-2-yl)-2,5-diphenyltetrazolium bromide (MTT) was added to each well according to the manufacturer's instructions. After $4 \mathrm{~h}$ in culture, the MTT medium was removed, and then DMSO was added into each well to dissolve the formazan. Cell viability was determined by measuring the absorbance at $490 \mathrm{~nm}$ using a Model 550 plate reader (Bio-Rad).

Cells were plated at 1,000 cells/well in 96-well plates. Cisplatin (Sigma) was added the following day at a concentration gradient $(0.5,2$ and $4 \mu \mathrm{g} / \mathrm{ml})$, in triplicate. After $48 \mathrm{~h}$, the cell survival rate (SR) $(\%)$ was determined using 

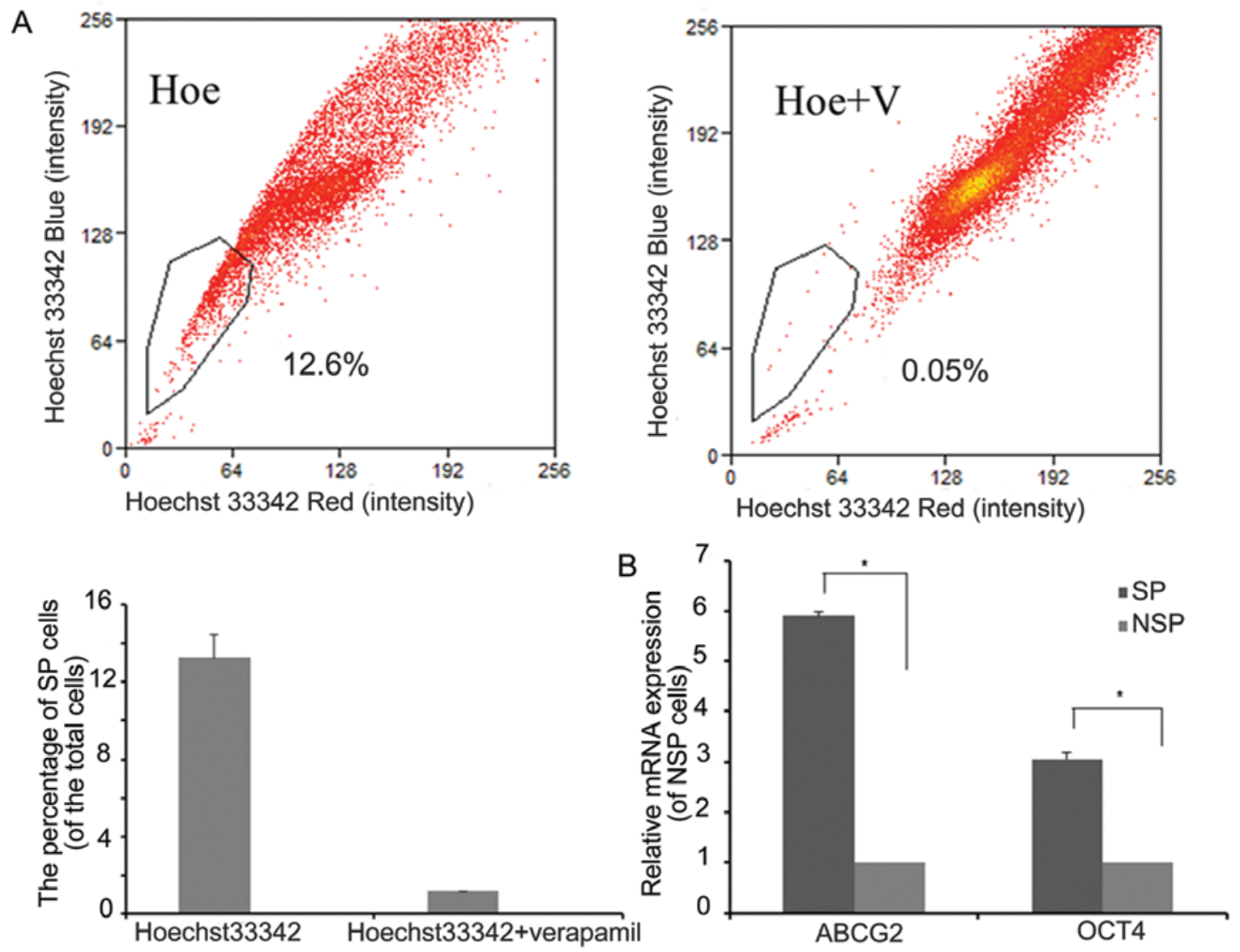

Figure 1. Identification of side population (SP) cells from the human bladder cancer T24 cells. (A) SP cells were sorted by flow cytometry using Hoechst 33342 (Hoe) from T24 cells with or without pretreatment with verapamil (V) for 30 min. (B) Relative mRNA expression of ABCG2 and OCT4 detected in SP and non-SP (NSP) T24 cells by real-time RT-PCR. GAPDH was used as an internal reference. The data are shown as means \pm standard deviation (SD). ${ }^{*}<0.05$ vs. NSP cells.

the MTT method. SR was calculated using the formula: SR $(\%)=($ mean absorbance of the test well/mean absorbance of the control) $x 100$. Inhibition rate (IR) was calculated as $\operatorname{IR}(\%)=100 \%-\mathrm{SR}(\%)$.

Cell migration assays. For assessment of cell migration in vitro, SP, NSP, SP-Bmil-siRNA cells and SP-scramble-siRNA cells ( $1 \times 10^{5}$ in $100 \mu 1$ of serum-free RPMI-1640 medium) were placed in the upper chamber of Transwell migration chambers with an $8-\mu \mathrm{m}$ pore size (BD Biosciences, Franklin Lakes, NJ, USA). The lower chamber contained $0.6 \mathrm{ml}$ of $10 \%$ FBS medium as a chemoattractant. Cells were incubated for $12 \mathrm{~h}$. Non-migrated cells were removed from the upper surface of the Transwell membrane with a cotton swab, and the migrated cells on the lower side of the membrane were fixed with $4 \%$ paraformaldehyde and stained with $0.25 \%$ crystal violet. After staining, cell migration was quantified by counting cells in 5 random fields (x200) under a microscope.

Self-renewal as assessed by tumor sphere formation. Cells were plated in ultra-low adhesion 6-well plates at a density of $1 \times 10^{4}$ cells/well and grown in a serum-free DMEM/F12 medium (Gibco) containing $20 \mathrm{ng} / \mathrm{ml}$ of epidermal growth factor (EGF; R\&D Systems, Minneapolis, MN, USA), $5 \mu \mathrm{g} / \mathrm{ml}$ of insulin, $0.4 \%$ bovine serum albumin (Gibco), and 2\% B27 (Invitrogen), as previously described (14). After 7 days in culture, the number of spheres was quantified by counting spheres in 5 random fields (x100) under a phase contrast microscope (Olympus).

Cell cycle analysis. For cell cycle analysis, SP cells transfected with Bmil-siRNA or scramble-siRNA were washed twice with PBS and fixed overnight with $70 \%$ ethanol at $-20^{\circ} \mathrm{C}$. Cells were then washed with PBS and incubated in PBS containing $50 \mu \mathrm{g} / \mathrm{ml} \mathrm{PI}, 0.2 \%$ Triton X-100, and $200 \mathrm{mg} / \mathrm{ml}$ RNase A for $30 \mathrm{~min}$ in the dark. Cell cycle distribution was analyzed using FACScan System (BD Diagnostics, Sparks, MD, USA). Data were analyzed with FlowJo software (Tree Star Inc., Ashland, OR, USA).

Mouse xenograft models. NOD/SCID mice $(\mathrm{n}=4$, male, 6-10 weeks of age) were purchased from the Laboratory Animal Center of the Sun Yat-Sen University (Guangzhou, China). All animal experiments were approved by the Animal Ethics and Welfare Committee of the Sun Yat-Sen University. SP cells $\left(1 \times 10^{5}\right)$ transfected with Bmil-siRNA or scramblesiRNA were suspended in RMPI-1640 and Matrigel (BD Biosciences, 1:1) and subcutaneously injected into the left and right sides of the back of recipient mice, respectively. Tumor formation was observed weekly for 6 weeks.

Statistical analysis. Data analysis was performed using SPSS 19.0 (SPSS Inc., Chicago, IL, USA). Data are expressed as means \pm standard deviation (SD). Differences between groups 


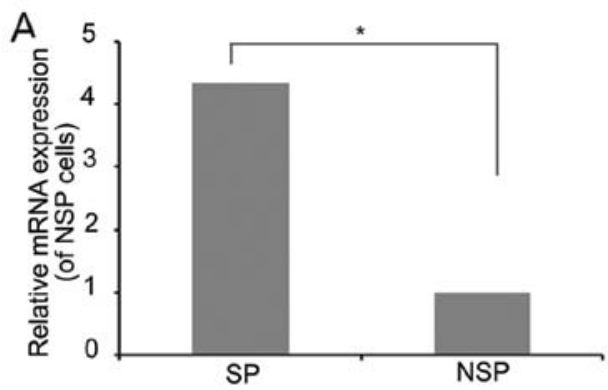

B

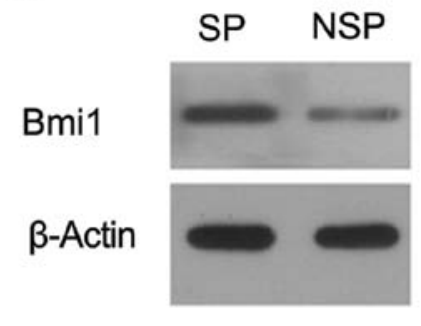

C
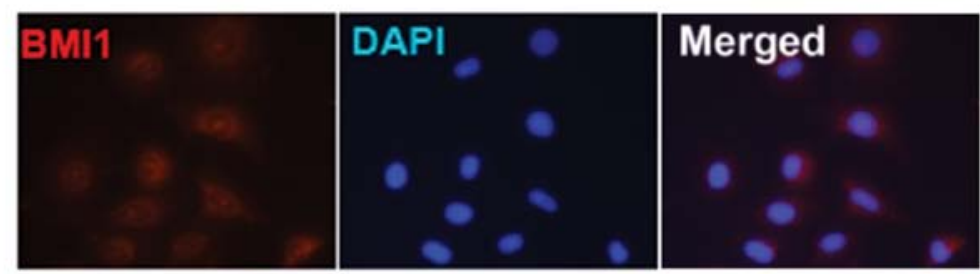

T24 NSP
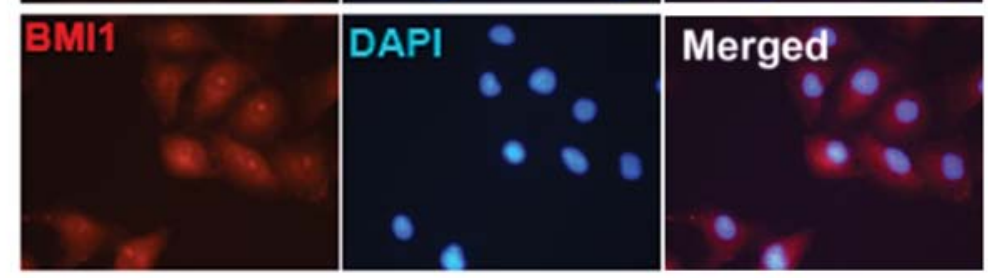

Figure 2. Bmil is highly expressed in SP T24 cells. (A) Relative expression of Bmil as detected in SP and NSP cells by real-time RT-PCR. GAPDH was used as internal reference. ${ }^{*} \mathrm{P}<0.05$ vs. NSP cells. (B) Western blot analyses of Bmil protein expression in SP and NSP cells. (C) Immunocytochemical analyses of Bmi1 protein expression. The nucleus was stained with DAPI (blue), and Bmil was stained with CY3 (red) (magnification, x200). The data are shown as means \pm SD.

were compared using the Student's t-test or one-way analysis of variance (ANOVA) with Fisher's least significant difference (LSD) test for post hoc analysis. Differences were considered to be statistically significant at $\mathrm{P}<0.05$.

\section{Results}

Identification of SP cells from human bladder cancer T24 cells. To explore the effect of Bmil in the maintenance of stem-like SP cells, the human bladder cancer cell line T24 was sorted by flow cytometry after incubation with Hoechst 33342 for $90 \mathrm{~min}$. SP cells represented $13.2 \pm 1.2 \%$ of the total cells. When preincubated with verapamil for $30 \mathrm{~min}$, the proportion of SP cells dropped to $0.05 \pm 0.01 \%$ of the total cells (Fig. 1A), which indicated that Hoechst 33342 exclusion is verapamilsensitive.

To determine whether SP cells had a stem cell phenotype, we compared the expression levels of cancer stem cell markers, such as Oct4 and ABCG2, between SP and NSP cells by real-time RT-PCR. The mRNA expression of ABCG2 and OCT4 was significantly higher in SP cells than in NSP (both $\mathrm{P}<0.05$ ) (Fig. 1B).

Bmil is highly expressed in SP cells when compared with the expression level in NSP cells. We observed that the mRNA expression of Bmi1 was upregulated 4.34 times in SP cells when compared with the expression level in NSP cells (Fig. 2A). Western blot and immunofluorescence analyses confirmed that Bmil was highly expressed in the nuclei and cytoplasm of SP cells when compared with the NSP cells (Fig. 2B and C). These results suggest that Bmil may play a regulatory role in the stem-like SP phenotype.
Effects of Bmil knockdown on the SP T24 cell phenotype, cell proliferation and migration in vitro. Our previous study confirmed that the purified SP cells can generate non-stemlike NSP cells through asymmetric cell division in vitro (17). Firstly, we transfected SP cells with Bmil siRNA and scramble siRNA for $48 \mathrm{~h}$, and the efficient knockdown of Bmil was confirmed by real-time RT-PCR and western blotting (Fig. 6A and B). Secondly, we transfected Bmil siRNA and scramble siRNA into the T24 cells (Fig. 3A), and the result showed that knockdown of Bmil reduced the proportion of SP cells from $12.26 \pm 1.3$ to $4.24 \pm 0.6 \%(\mathrm{P}<0.01)$ in the T24 cells. Thirdly, we transfected Bmil siRNA and scramble siRNA into purified SP cells and cultured them for 10 days to examine the role of Bmil in this process. The SP subpopulation in the Bmil siRNA group was decreased when compared with the negative control cells $(13.32 \pm 2.2$ vs. $38.98 \pm 3.2 \%, \mathrm{P}<0.01$; Fig. $3 \mathrm{~B})$. These results demonstrate that Bmil plays an important role in maintaining SP cell self-renewal and differentiation abilities, and knockdown of Bmil promoted SP cell differentiation toward non-stem-like NSP cells.

We then detected the proliferation and migration abilities of SP and NSP cells using MTT and Transwell assays. The cell growth curve indicated that the SP cells proliferated faster than the NSP cells after day 2 (Fig. 3C). In the Transwell assay, more SP cells penetrated through the gel membrane compared with NSP cells $(\mathrm{P}<0.01)$ (Fig. 3E). After transfection with siRNA targeting Bmil, the proliferation and migration of SP-Bmil-siRNA cells were sharply decreased compared with the SP-scramble-siRNA cells (Fig. 3D and E).

Bmil regulates the self-renewal capacity of SP cells. Tumor sphere generation in vitro is considered to be indicative of self- 


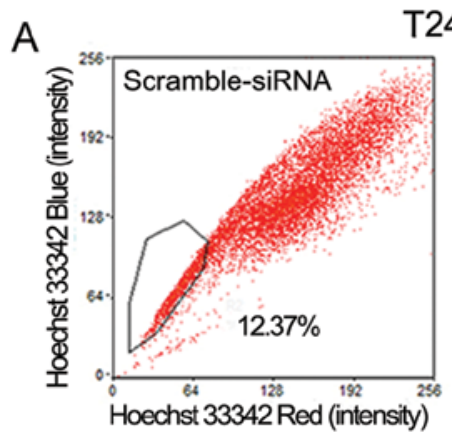

T24 cells
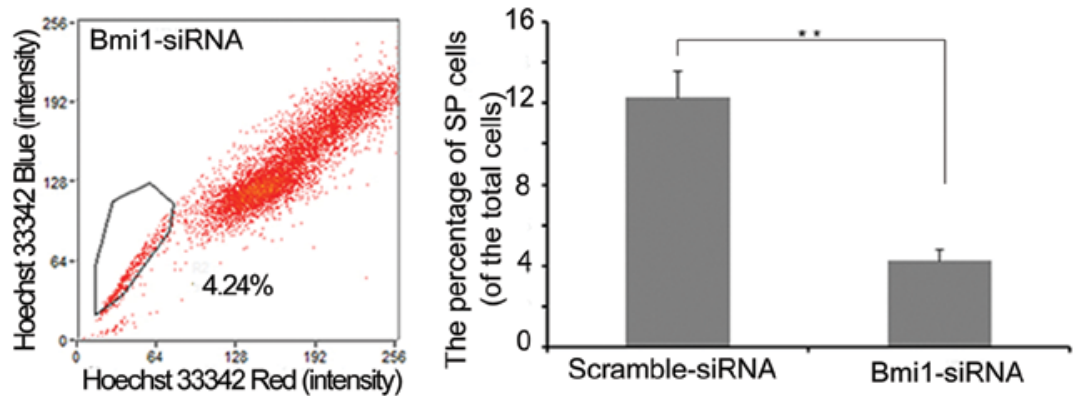

B

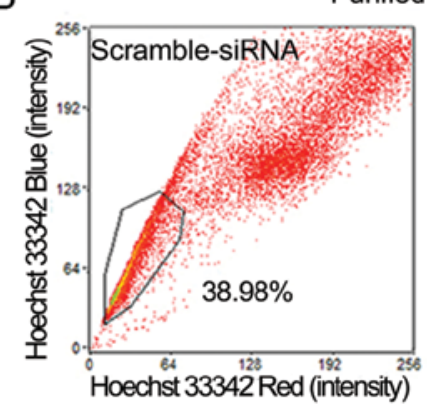

Purified T24 SP cells

C

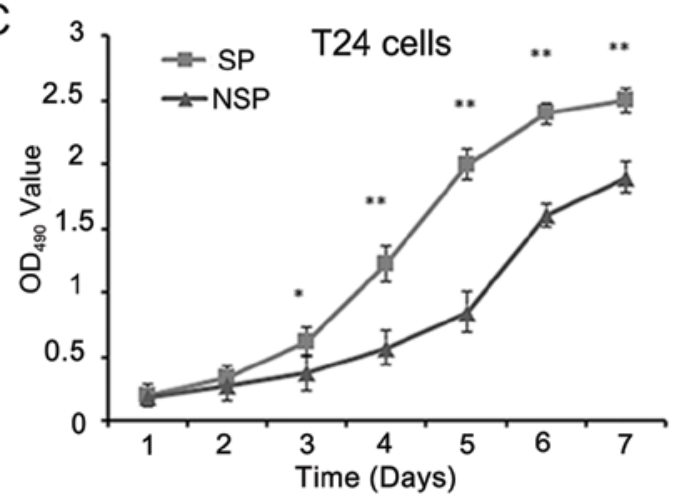

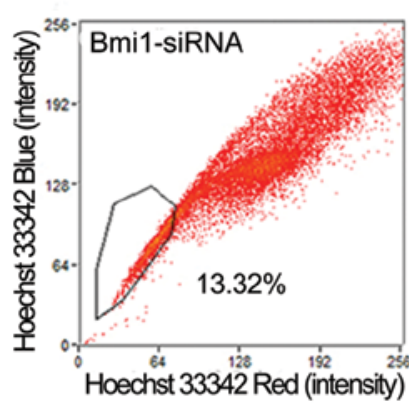

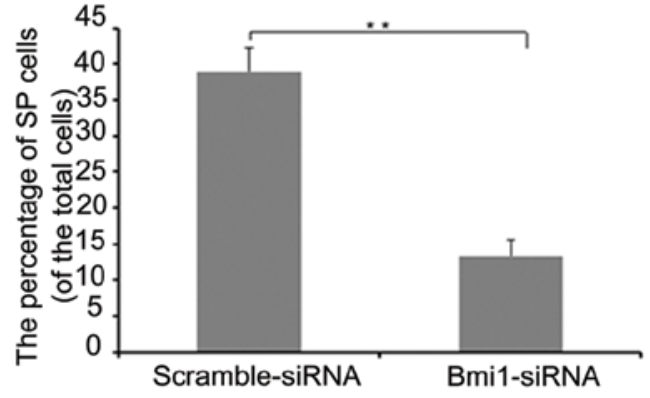

E

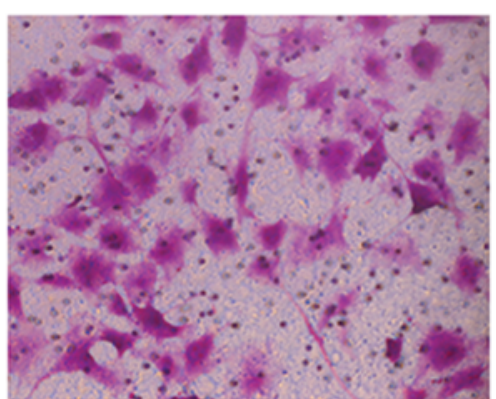

SP

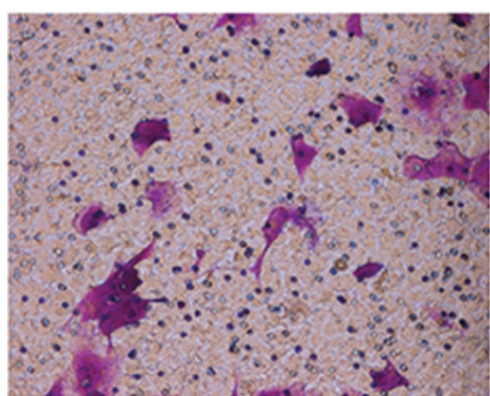

NSP
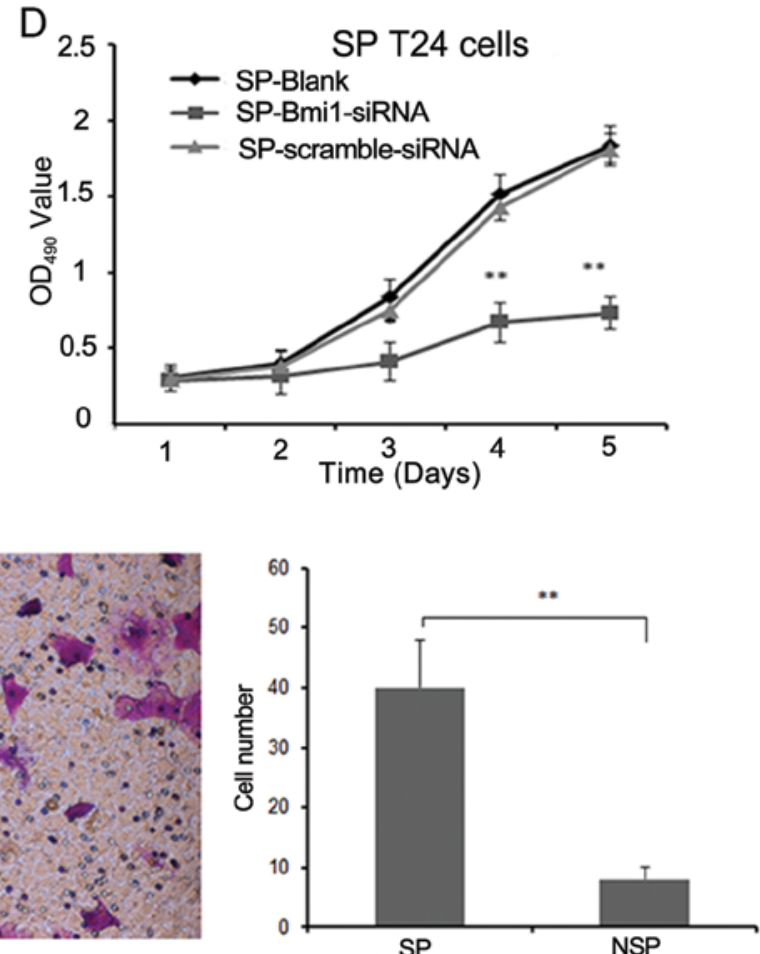

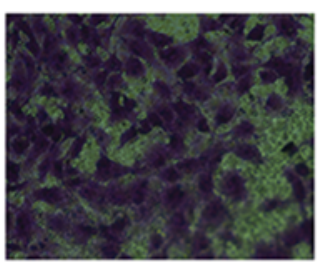

SP-Blank

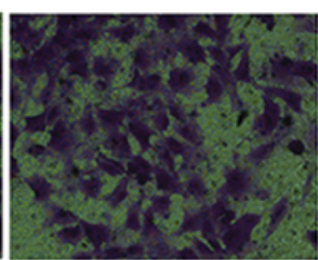

SP-scramble-siRNA

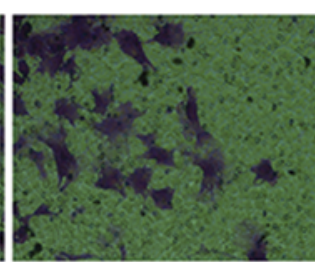

SP-Bmi1-siRNA

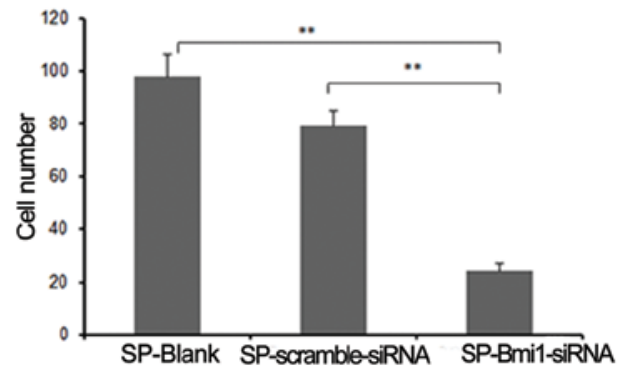

Figure 3. Effects of Bmil knockdown on SP T24 cell phenotype, cell proliferation and migration in vitro. SP cells were sorted by flow cytometry using Hoechst 33342 in T24 cells (A) and purified T24 SP cells (B) after Bmil knockdown and long-term culture (10 days). (C) SP and NSP cell proliferation was monitored by MTT assays for 7 days. (D) SP cell proliferation after knockdown of Bmil, as assessed by the MTT assays for 5 days. ${ }^{*} \mathrm{P}<0.05,{ }^{* *} \mathrm{P}<0.01$ vs. SP-scramble-siRNA. (E) The cell migration capacity was analyzed by Transwell assays. Five random fields (magnification, x200) were photographed and cells were counted. The data are shown as means $\pm \mathrm{SD}$. ${ }^{*} \mathrm{P}<0.05,{ }^{* *} \mathrm{P}<0.01$. 

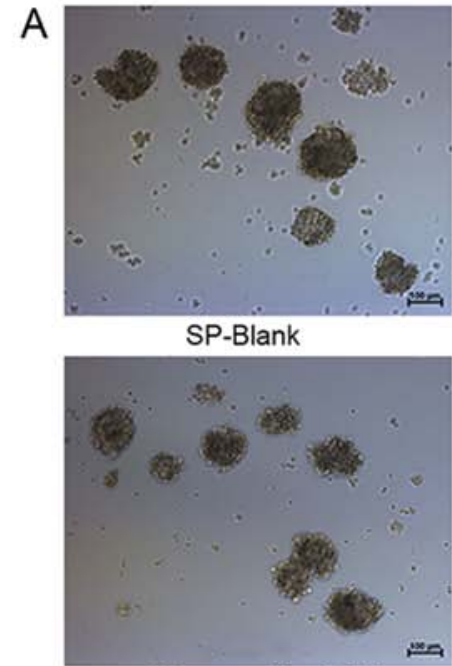

SP-scramble-siRNA

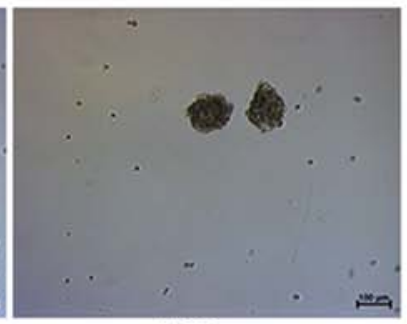

NSP

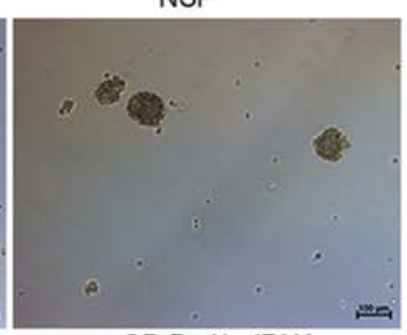

SP-Bmi1-siRNA
B

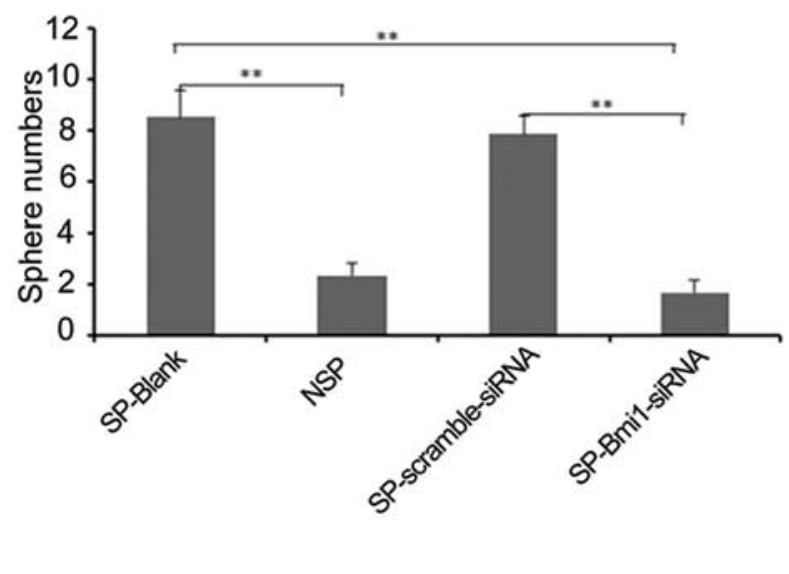

Figure 4. Bmil regulates the self-renewal of SP T24 cells in vitro. (A) Tumor sphere formation assay was used to assess the self-renewal capacity of SP and NSP cells. Scale bar, $100 \mu \mathrm{m}$. (B) Self-renewal capacity of SP cells after Bmil knockdown. Five random fields (x100) were photographed, and the sphere numbers were counted after 7 days. The data are shown as means \pm SD. ${ }^{* *} \mathrm{P}<0.01$.

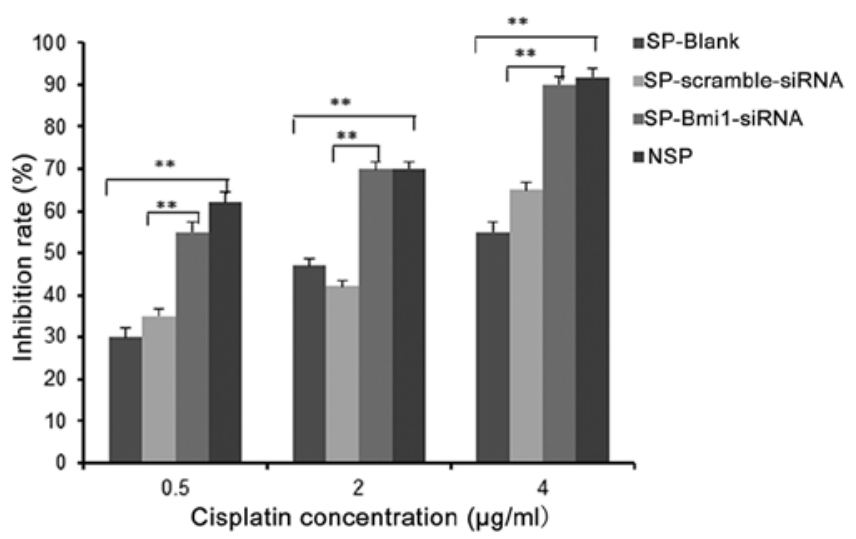

Figure 5. Bmil knockdown enhances SP T24 cell sensitivity to cisplatin. SP, NSP, SP-Bmi-siRNA and SP-scramble-siRNA cells were treated with various concentrations of cisplatin $(0.5,2$ and $4 \mu \mathrm{g} / \mathrm{ml})$ for $48 \mathrm{~h}$, and the inhibition rate (IR) was detected by MTT assays. Survival rate (SR) $(\%)=($ mean absorbance of the test well/mean absorbance of the control) $x 100 \%$. Inhibition rate (IR) was calculated as IR $(\%)=100 \%$ - SR $(\%)$. The data are shown as means \pm SD. ${ }^{* *} \mathrm{P}<0.01$.

renewal potential, one of the characteristics of CSCs (15). We assessed the self-renewal properties of SP cells by detecting their ability to form tumor spheres in serum-free media and nonadherent conditions. Results showed that the number of tumor spheres formed by SP cells was nearly four times higher than that for NSP cells. In order to ascertain whether Bmil regulates the self-renewal capacity of SP cells, we silenced the Bmil expression in SP cells using siRNA, and the results of the sphere formation assay showed that this ability of SP cells was significantly inhibited compared with that of SP-scramble- siRNA cells $(\mathrm{P}<0.01)$ (Fig. 4). These data revealed that Bmil plays an important role in regulating the self-renewal ability of SP cells.

Bmil knockdown enhances SP cell sensitive to cisplatin in vitro. Chemoresistance is considered to be one of the char- acteristics of CSCs (16). We previously reported that the SP cells sorted from the T24 cells were significantly more resistant to chemotherapy when compared with the resistance of NSP cells (17). In order to ascertain whether Bmil knockdown influences cisplatin sensitivity of SP cells, we treated SP, NSP, SP-Bmil-siRNA and SP-scramble-siRNA cells with various concentrations of cisplatin for $48 \mathrm{~h}$ (Fig. 5). We then observed the inhibition rate (IR) of each cell group by MTT assays. Results revealed that SP cells showed a stronger resistance to cisplatin compared with the NSP cells at all concentrations (all $\mathrm{P}<0.01$ ). After knockdown of Bmi1, the IR of the SP-Bmil-siRNA cells was obviously higher when compared with the IR of the SP-scramble-siRNA cells (all $\mathrm{P}<0.01$ ). These results demonstrated SP chemoresistance and that Bmi1 knockdown could sensitize SP cells to cisplatin.

Bmil knockdown induces cell cycle arrest in the G0/G1 phase through derepression of the p16 ${ }^{I N K 4 a} / p 14^{A R F}$ locus in SP T24 cells. Bmil has been shown to be important for the self-renewal of neural stem cells by inhibition of the $\mathrm{p} 16^{\mathrm{INK} 4 \mathrm{a}} / \mathrm{p} 14^{\mathrm{ARF}}$ locus (18). To ascertain whether knockdown of Bmil results in the upregulation of $\mathrm{p} 16^{\mathrm{INK} 4 \mathrm{a}} / \mathrm{p} 14^{\mathrm{ARF}}$, we transfected SP cells with Bmil siRNA and scramble siRNA for $48 \mathrm{~h}$. The expression of p16 $6^{\mathrm{INK} 4 \mathrm{a}}$ and $\mathrm{p} 14^{\mathrm{ARF}}$ was upregulated at the mRNA and protein levels (Fig. 6A and B). We also assessed the relationship between Bmil knockdown and cell cycle progression by flow cytometric analysis (Fig. 6C). Compared with the negative control SP cells, Bmil knockdown caused a significant decrease in the proportion of S-phase cells (from $43.8 \pm 1.5$ to $20.9 \pm 1.9 \%, \mathrm{P}<0.01$ ) and a significant increase in the proportion of G0/G1-phase cells (from $46.7 \pm 2.0$ to $65.4 \pm 1.6 \%, \mathrm{P}<0.05$ ). These results suggest that Bmil promotes stem-like SP cell proliferation by regulating cell cycle progression through suppression of the $\mathrm{p} 16^{\mathrm{INK} 4 \mathrm{a}} / \mathrm{p} 14^{\mathrm{ARF}}$ locus.

Bmil knockdown suppresses the tumorigenicity of SP T24 cells in vivo. To further explore the role of Bmil in the tumorigenesis 

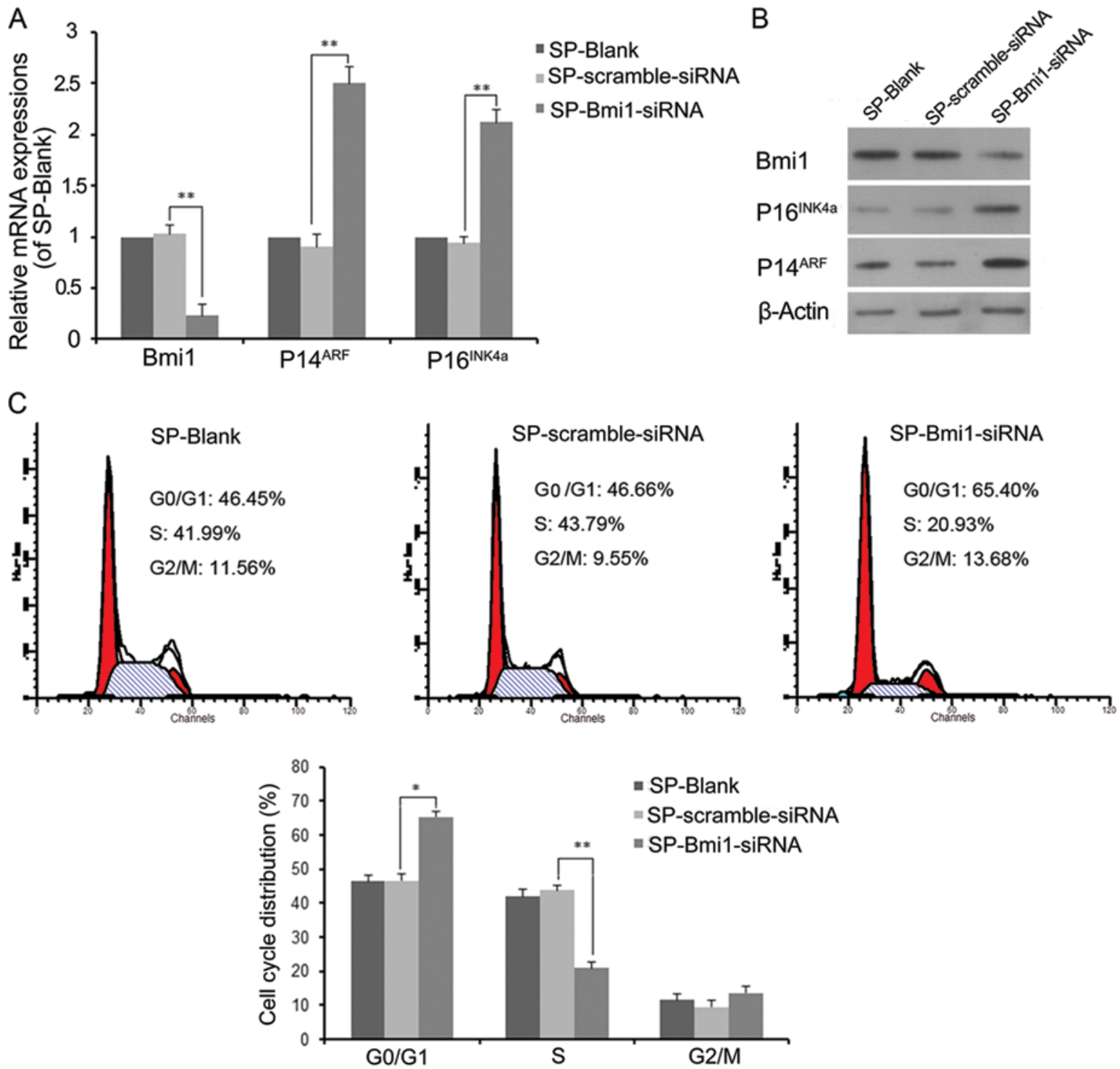

Figure 6. Bmil knockdown inhibits cell cycle progression through derepression of the p16 $6^{\mathrm{INK} 4 a} / \mathrm{p} 14^{\mathrm{ARF}}$ locus in SP T24 cells. (A) Bmi1, p16 $6^{\mathrm{INK} 4 \mathrm{a}}$ and $\mathrm{p} 14^{\mathrm{ARF}}$ mRNA expression was determined by real-time RT-PCR. GAPDH was used as an internal reference. (B) Bmil, p16 ${ }^{\mathrm{INK} 4 \mathrm{a}}$ and p1 $^{\mathrm{ARF}}$ protein expression was determined by western blotting. $\beta$-actin was used as an internal reference. (C) Cell cycle progression in SP cells after Bmil knockdown was determined by flow cytometric analysis using propidium iodide (PI) staining. The data are shown as means $\pm \mathrm{SD} .{ }^{*} \mathrm{P}<0.05,{ }^{* *} \mathrm{P}<0.01$.

of bladder cancer CSCs in vivo, equal numbers of SP-BmilsiRNA and SP-scramble-siRNA cells were subcutaneously injected into the left and right sides of the back of recipient mice, respectively. The development of tumors was detected throughout the 6 weeks after injection. The SP-scramblesiRNA cells generated varying sizes of tumors in all four mice (Fig. 7B). In contrast, SP-Bmil-siRNA cells failed to form subcutaneous tumors in any of the recipient mice (Fig. 7A). Results of hematoxylin and eosin (H\&E) staining (Fig. 7C) showed that the tumors formed from the subcutaneously injected SP-scramble-siRNA cells was a typical urothelial carcinoma. This in vivo result further supports that Bmil is essential for the tumorigenic capacity of SP T24 cells.

\section{Discussion}

Increasing evidence supports the existence of CSCs, which are considered to be responsible for tumor initiation, tumor recurrence and therapy resistance $(4,5)$. Therefore, a better understanding of the biology and regulatory mechanisms of CSCs is of great significance for developing new strategies targeting CSCs for cancer treatment (11). In a previous study, we enriched bladder cancer stem cells from the T24 cell line and characterized their CSC properties (17). Furthermore, SP-enriched cells possessing stem cell characteristics have been identified in a number of cancers $(4,8,9)$.

We used SP cells as a bladder cancer stem cell model to elucidate their self-renewal and tumor initiation mechanisms. In the present study, we observed that SP cells from the T24 cell line possessed CSC properties and that Bmil was highly expressed in the SP population when compared with that in the NSP cells. Our results also demonstrated that Bmil plays an important role in regulating proliferation, self-renewal and tumorigenic properties of SP cells by the inhibition of the $16^{\mathrm{INK} 4 \mathrm{a}} / \mathrm{p} 14^{\mathrm{ARF}}$ locus. Knockdown of Bmil expression by siRNA sensitized SP cells to cisplatin and suppressed their tumorigenicity in vitro and in vivo. 


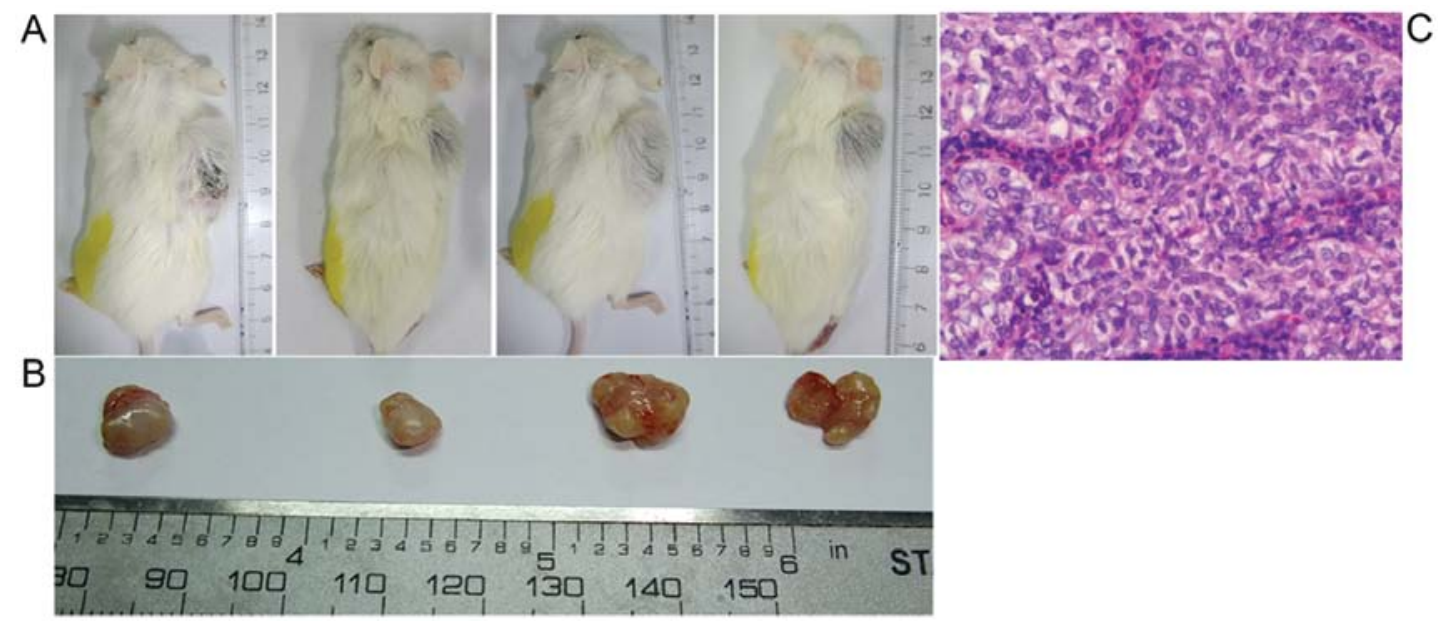

Figure 7. Bmil silencing suppresses the tumorigenicity of SP T24 cells in vivo. (A) SP-Bmi1-siRNA and SP-scramble-siRNA T24 cells (1x105) were subcutaneously injected into the left and right sides of the back of recipient mice, respectively. The mice were sacrificed 6 weeks later. (B) Sizes of the tumors formed from subcutaneously injected SP-scramble-siRNA T24 cells. (C) Results of hematoxylin and eosin (H\&E) staining showed that the tumor formed from subcutaneously injected SP-scramble-siRNA T24 cells was a typical urothelium carcinoma (magnification, x100).

CSCs are characterized by self-renewal, chemoresistance and tumorigenesis (19). To identify CSCs among tumor cells, two different methods are usually proposed. The first is to use surface markers selectively expressed on CSCs. However, in many tumor types, no markers are known to prospectively identify CSCs; in such cases, the ability of stem cells to extrude dyes such as Hoechst 33342 can be used to identify them (20). Thus, in a number of tumors and cancer cell lines, SP cells have been isolated and identified to be potential candidates for CSCs $(9,20-22)$. The ATP-binding cassette transporter ABCG2/BCRP1 has been revealed to be the main mediator of the SP phenotype $(23,24)$. In contrast, some studies have demonstrated that in some normal tissues or certain tumors, SP cells are not enriched in stem-like cells (25-27). Triel et al (27) demonstrated that SP cells found within human epidermis lack stem cell characteristics, and Broadley et al (28) revealed that SP cells from glioblastoma multiforme cell lines had no stemlike activity in vitro and in vivo when compared with these characteristics in non-SP and parental cells. These conflicting data indicate that SP cells are not necessarily stem cells and that further characterization is necessary to prove their nature. In one of our previous studies (17) and in the present study, results showed that SP cells exhibited a stronger ability for proliferation, self-renewal and chemoresistance than NSP cells in the bladder cancer cell line T24. Furthermore, SP cells had high expression of ABCG2 and stem cell marker OCT4 when compared with that in the NSP cells. Our results suggest that SP cells can serve as a model for the study of bladder CSCs.

Bmil, a component of PRC1, is thought to be essential for maintaining self-renewal in several normal stem cell systems and CSCs, including haematopoietic stem cells (12), neural stem cells (18) and leukemic stem cells (29). Recent studies have demonstrated that Bmil is highly expressed and regulates the stem-like properties of SP cells in hepatocellular carcinoma, breast cancer and pancreatic adenocarcinoma (30-32). In our previous studies, Bmil was found to be highly expressed in bladder cancer specimens and to be correlated to clinicopathological characteristics and patient prognosis $(33,34)$. Therefore, we hypothesized that Bmil may also play an important regula- tory role in bladder CSCs. In the present study, we functionally validated the importance of Bmil expression in stem-like SP cells from the bladder cancer cell line T24. As expected, our results showed that both the mRNA and protein levels of Bmil were higher in SP cells. Knockdown of Bmil by siRNA significantly decreased the proportion of SP cells among the T24 cells and purified SP cells after long-term differentiation. Furthermore, analysis of the growth, migration and tumor sphere formation of purified SP cells transfected with siRNA revealed that loss of Bmil caused a considerable inhibition in the proliferation and self-renewal of SP cells. These observations were further confirmed by xenograft transplantation in NOD/SCID mice, where Bmil knockdown in SP cells resulted in the failure to develop tumors.

Bmil has been reported to be associated with the protection of cancer cells from apoptosis induced by chemotherapy. Yin et al (35) observed that Bmil promoted the chemoresistance of pancreatic cancer cells to gemcitabine. Recently, Wang et al (36) reported that Bmil enhanced the chemoresistance of ovarian cancer cells, and that silencing Bmil sensitized ovarian cancer cells to cisplatin. A previous study also showed that CTCs extracted from T24 cells were resistant to cisplatin, and that this resistance was related to aldehyde dydrogenase (37); however, the relationship between Bmil and aldehyde dydrogenase is unknown. Another study showed that the cisplatin resistance of T24 SP cells was correlated with Bmil, and that Bmil was also correlated with Nanog expression (38). Consistent with these reports, our results revealed that SP cells from bladder cancer cells showed a stronger resistance to cisplatin, and that Bmil knockdown significantly increased the IR by cisplatin in SP cells. These results strongly suggest that Bmil is essential for maintaining tumorigenesis and chemoresistance in stem-like SP cells.

However, the molecular mechanisms of Bmil function in CSCs are not completely understood. Some studies revealed that Bmil preserves the self-renewal and proliferation characteristics of stem cells through the repression of the $\mathrm{p} 16^{\mathrm{INK} 4 a} / \mathrm{p} 14^{\mathrm{ARF}}$ locus, which encodes two tumor-suppressor 
proteins (P16Ink4a and P14Arf) $(18,39,40)$. Conversely, some studies revealed an $\mathrm{p} 16^{\mathrm{INK} 4 \mathrm{a}} / \mathrm{p} 14^{\mathrm{ARF}}$-independent contribution of Bmil to self-renewal in neural stem cells and tumorigenesis in a hepatocellular carcinoma mouse model $(41,42)$. Douglas et al (43) reported that Bmil knockdown significantly inhibited cell proliferation in both wild-type and p16 ${ }^{\mathrm{INK} 4 \mathrm{a}}$-null Ewing sarcoma. Nevertheless, the molecular mechanisms by which Bmil affects CSCs in human bladder cancer have not been previously identified. In the present study, we observed that Bmil knockdown using siRNA could promote $\mathrm{p} 16^{\mathrm{INK} 4 \mathrm{a}} / \mathrm{p} 14^{\mathrm{ARF}}$ mRNA and protein expression in stem-like SP cells from the human bladder cancer cell line T24. Bmil knockdown also caused S-phase cell cycle arrest in bladder cancer T24 SP cells. These results demonstrated that Bmil is involved in stem-like SP cell self-renewal and tumorigenesis through the repression of the $\mathrm{p} 16^{\mathrm{INK} 4 \mathrm{a}} / \mathrm{p} 14^{\mathrm{ARF}}$ locus in the human bladder cancer cell line T24.

In conclusion, our results demonstrated that the SP phenotype can be used to isolate CSCs in the bladder cancer cell line T24, and that Bmi-1 modulates various cancer stem-like characteristics of bladder cancer SP cells, such as self-renewal, chemoresistance and tumorigenesis. In addition, Bmil performed these functions to a great extent through the suppression of the $\mathrm{p} 16^{\mathrm{INK} 4 \mathrm{a}} / \mathrm{p} 14^{\mathrm{ARF}}$ locus. Based on our findings, Bmil may be a target by which to decrease the CSC population of tumors and to improve treatment outcomes.

\section{Acknowledgements}

This study was supported by grants from the National Natural Science Foundation of China (no. 81072102 to W. Xie) and the Collaborative Funds from Panyu Hospital of Chinese Medicine.

\section{References}

1. Han S, Zhang S and Chen W: Analysis of the status and trends of bladder cancer incidence in China. Oncol Progress 11: 89-95, 2013.

2. Ploeg M, Aben KK and Kiemeney LA: The present and future burden of urinary bladder cancer in the world. World J Urol 27 289-293, 2009

3. Babjuk M, Burger M, Zigeuner R, et al: EAU guidelines on non-muscle-invasive urothelial carcinoma of the bladder: update 2013. Eur Urol 64: 639-653, 2013.

4. Enderling H, Hlatky L and Hahnfeldt P: Cancer stem cells: a minor cancer subpopulation that redefines global cancer features. Front Oncol 3: 76, 2013

5. Reya T, Morrison SJ, Clarke MF and Weissman IL: Stem cells, cancer, and cancer stem cells. Nature 414: 105-111, 2001.

6. Siddique HR and Saleem M: Role of BMI1, a stem cell factor, in cancer recurrence and chemoresistance: preclinical and clinical evidences. Stem Cells 30: 372-378, 2012.

7. Sugihara E and Saya H: Complexity of cancer stem cells. Int J Cancer 132: 1249-1259, 2013.

8. Kondo T: Stem cell-like cancer cells in cancer cell lines. Cancer Biomark 3: 245-250, 2007.

9. Wu C and Alman BA: Side population cells in human cancers. Cancer Lett 268: 1-9, 2008.

10. Park IK, Morrison SJ and Clarke MF: Bmi1, stem cells, and senescence regulation. J Clin Invest 113: 175-179, 2004.

11. Jacobs JJ, Kieboom K, Marino S, DePinho RA and van Lohuizen M: The oncogene and Polycomb-group gene bmi-1 regulates cell proliferation and senescence through the ink4a locus. Nature 397: 164-168, 1999.

12. Park IK, Qian D, Kiel M, et al: Bmi-1 is required for maintenance of adult self-renewing haematopoietic stem cells. Nature 423 : 302-305, 2003
13. Siddique HR, Parray A, Tarapore RS, et al: BMI1 polycomb group protein acts as a master switch for growth and death of tumor cells: regulates TCF4-transcriptional factor-induced BCL2 signaling. PLoS One 8: e60664, 2013.

14. Fan X, Chen X, Deng W, Zhong G, Cai Q and Lin T: Up-regulated microRNA-143 in cancer stem cells differentiation promotes prostate cancer cells metastasis by modulating FNDC3B expression. BMC Cancer 13: 61, 2013.

15. Ponti D, Costa A, Zaffaroni N, et al: Isolation and in vitro propagation of tumorigenic breast cancer cells with stem/progenitor cell properties. Cancer Res 65: 5506-5511, 2005

16. Tang C, Ang BT and Pervaiz S: Cancer stem cell: target for anticancer therapy. FASEB J 21: 3777-3785, 2007.

17. Ning ZF, Huang YJ, Lin TX, et al: Subpopulations of stem-like cells in side population cells from the human bladder transitional cell cancer cell line T24. J Int Med Res 37: 621-630, 2009.

18. Molofsky AV, He S, Bydon M, Morrison SJ and Pardal R: Bmi-1 promotes neural stem cell self-renewal and neural development but not mouse growth and survival by repressing the $16^{\text {Ink4a }}$ and p19 $9^{\text {Arf }}$ senescence pathways. Genes Dev 19: 1432-1437, 2005.

19. Cetin I and Topcul M: Cancer stem cells in oncology. J BUON 17: 644-648, 2012

20. Moserle L, Ghisi M, Amadori A and Indraccolo S: Side population and cancer stem cells: therapeutic implications. Cancer Lett 288: 1-9, 2010.

21. Ho MM, Ng AV, Lam S and Hung JY: Side population in human lung cancer cell lines and tumors is enriched with stem-like cancer cells. Cancer Res 67: 4827-4833, 2007.

22. Oates JE, Grey BR, Addla SK, et al: Hoechst 33342 side population identification is a conserved and unified mechanism in urological cancers. Stem Cells Dev 18: 1515-1522, 2009.

23. Zhou S, Schuetz JD, Bunting KD, et al: The ABC transporter Bcrp1/ABCG2 is expressed in a wide variety of stem cells and is a molecular determinant of the side-population phenotype. Nat Med 7: 1028-1034, 2001.

24. Hepburn AC, Veeratterapillay R, Williamson SC, et al: Side population in human non-muscle invasive bladder cancer enriches for cancer stem cells that are maintained by MAPK signalling. PLoS One 7: e50690, 2012

25. Stingl J, Eirew P, Ricketson I, et al: Purification and unique properties of mammary epithelial stem cells. Nature 439: 993-997, 2006.

26. Mitsutake N, Iwao A, Nagai K, et al: Characterization of side population in thyroid cancer cell lines: cancer stem-like cells are enriched partly but not exclusively. Endocrinology 148: 1797-1803, 2007.

27. Triel C, Vestergaard ME, Bolund L, Jensen TG and Jensen UB: Side population cells in human and mouse epidermis lack stem cell characteristics. Exp Cell Res 295: 79-90, 2004.

28. Broadley KW, Hunn MK, Farrand KJ, et al: Side population is not necessary or sufficient for a cancer stem cell phenotype in glioblastoma multiforme. Stem Cells 29: 452-461, 2011.

29. Lessard J and Sauvageau G: Bmi-1 determines the proliferative capacity of normal and leukaemic stem cells. Nature 423: 255-260, 2003.

30. Chiba T, Miyagi S, Saraya A, et al: The polycomb gene product BMI1 contributes to the maintenance of tumor-initiating side population cells in hepatocellular carcinoma. Cancer Res 68: 7742-7749, 2008.

31. Liu S, Dontu G, Mantle ID, et al: Hedgehog signaling and Bmi-1 regulate self-renewal of normal and malignant human mammary stem cells. Cancer Res 66: 6063-6071, 2006.

32. Proctor E, Waghray M, Lee CJ, et al: Bmil enhances tumorigenicity and cancer stem cell function in pancreatic adenocarcinoma. PLoS One 8: e55820, 2013.

33. Qin ZK, Yang JA, Ye YL, et al: Expression of Bmi-1 is a prognostic marker in bladder cancer. BMC Cancer 9: 61, 2009.

34. Liang W, Zhu D, Cui X, et al: Knockdown BMI1 expression inhibits proliferation and invasion in human bladder cancer T24 cells. Mol Cell Biochem 382: 283-291, 2013.

35. Yin $\mathrm{T}$, Wei $\mathrm{H}$, Leng $\mathrm{Z}$, et al: Bmi-1 promotes the chemoresistance, invasion and tumorigenesis of pancreatic cancer cells. Chemotherapy 57: 488-496, 2011.

36. Wang E, Bhattacharyya S, Szabolcs A, et al: Enhancing chemotherapy response with Bmi-1 silencing in ovarian cancer. PLoS One 6: e17918, 2011.

37. Falso MJ, Buchholz BA and White RW: Stem-like cells in bladder cancer cell lines with differential sensitivity to cisplatin. Anticancer Res 32: 733-738, 2012.

38. Zhang Y, Wang Z, Yu J, et al: Cancer stem-like cells contribute to cisplatin resistance and progression in bladder cancer. Cancer Lett 322: 70-77, 2012. 
39. Molofsky AV, Pardal R, Iwashita T, Park IK, Clarke MF and Morrison SJ: Bmi-1 dependence distinguishes neural stem cell selfrenewal from progenitor proliferation. Nature 425: 962-967, 2003.

40. Biehs B, Hu JK, Strauli NB, et al: BMI1 represses Ink4a/Arf and Hox genes to regulate stem cells in the rodent incisor. Nat Cell Biol 15: 846-852, 2013.

41. Fasano CA, Dimos JT, Ivanova NB, Lowry N, Lemischka IR and Temple S: shRNA knockdown of Bmi-1 reveals a critical role for p21-Rb pathway in NSC self-renewal during development. Cell Stem Cell 1: 87-99, 2007.
42. Xu CR, Lee $\mathrm{S}$, Ho C, et al: Bmil functions as an oncogene independent of Ink4A/Arf repression in hepatic carcinogenesis. Mol Cancer Res 7: 1937-1945, 2009.

43. Douglas D, Hsu JH, Hung L, et al: BMI-1 promotes Ewing sarcoma tumorigenicity independent of CDKN2A repression. Cancer Res 68: 6507-6515, 2008. 